\title{
Focus Group 4 - Connectivity and networking
}

Chair: Ferrán Ruiz Tarragó (Spain)

Rapporteurs: Don Passey (UK) and Sigrid Schubert (Germany)

Participants: Doug Brown (UK), Jan Hylén (Sweden), Jef Moonen

(Netherlands), Miguel Reyes (Chile), Jimena Sepúlveda (Chile), Juan Vargas (Chile), Terry White (UK)

Keywords: Networking, challenges, future skills, virtual school, learning school

\section{INTRODUCTION}

The discussions concerned the concepts of connectivity and networking. The discussions covered factors involved in a range of aspects of developing connectivity and networking in relation to emerging and new educational systems. Four aspects were considered: 1)How will networking challenge school function? 2) Future skills and competencies required. 3)The virtual school. and 4)The child in the learning society.

\section{HOW WILL NETWORKING CHALLENGE SCHOOL FUNCTION?}

It is clear that the development of connectivity and networking to support traditional and emerging educational systems arises from two fundamental, and different, perspectives: central concerns (such as concepts of how centralist provision might operate); and individual concerns (such as concepts of the benefits and advantages to the individual learner). Currently there are a number of drivers which are likely to challenge current school function. In a number of countries it is recognised that the transition from 
primary to secondary schools is often associated with a decline in levels of engagement, interest, attendance, positive attitude, and learning attainment of pupils. This decline is associated with shifts towards student dissatisfaction, and towards parental perceptions and expectations of dissatisfaction with current educational provision from schools. Under these circumstances it is clear that both students and parents could opt for what might be considered better alternative systems of education based outside or alongside schools. Changing attitudes towards learning engagement have been recognised when computers have been made accessible in areas on the streets of towns in Brazil, for example. In other countries parents in some areas are already choosing to support their children at home when the time comes for them to revise for.

For schools which have already become involved in shifts towards greater provision via connectivity and networking, it has been found that this has often been associated with circumstances where there have been financial pressures for change. Schools have responded in shifts towards alternative provision when financial resources have become more limited. Even when financial resources are not limited, positive increases in home learning have been found in some countries.

In some countries companies and organisations have already been involved in the production of resources to support school learning at home.Under these circumstances the involvement of stakeholders can shift significantly. The constitution of stakeholder and business involvement will be a need for consideration by schools in the future. Some countries are already considering the potential advantages or needs to shift from a subjectbased to a topic-based, or theme-based, curriculum. For a theme-based curriculum, the Internet offers, through resource links to relevant and up-todate material, ideal opportunities for provision to meet the needs of students who might want to pursue their learning in these ways.

The challenge to school function is based on shifts in power and control. In terms of power, the shift can be from schools towards parents. In terms of control, the shift can be from that held by teachers, towards students.

\section{FUTURE SKILLS AND COMPETENCIES}

In terms of future skills and competencies required, students will clearly require an understanding of facility of use, in terms of a literacy in handling of information, as well as appropriate skills to use and create networking. Managing continuous change will be a future skill and competency need not only for school managers, and teachers, but also for students themselves. 


\section{THE VIRTUAL SCHOOL}

The development in practice of virtual will require an understanding of both the strengths and weaknesses of virtual schools, if such schools are to retain key strengths as well as to develop other key strategies. An understanding of the costs of setting up virtual schools will also be needed, although costings prepared to date (in Sweden, and in the UK) suggest that costs are comparable to the setting up of traditional schools.

A problem which the setting up of virtual schools may face is that many will need to start from traditional starting points. It seems important that developmental experiments start from different positions: from traditional school, existing virtual school, and 'green field' starting points. Examples already exist of virtual schools in some countries. In other countries, shifts in organisational practices have been identified in traditional schools moving towards more virtual school situations. The production and sale of specialist expertise and resources has also been developed by certain schools at this stage. Revision material, supporting individual endeavour, and offering lesson objectives, linked resources, and schemes of work for courses run in the school, has enabled some students to work on materials outside school and to attain at substantially earlier times than some of their peers. The use of laptops is also enabling some schools to become mobile schools.

A range of factors is affecting, and will affect in the future, the ways in which implementation and practice of virtual schools can develop. There is a clear role of vision, but where schools are subject to successive initiatives that need to be rationalised, this can lead to a response to vision which can lead to a 'crisis vision' rather than an informed vision. Under such circumstances, mechanisms of integration of initiatives become more vitally important. A virtual school development will need to consider the factor of how continuity of training and development will be handled, as developments of this nature will be concerned with continuous change rather than with a period of change moving developments to a new plateau position. Monitoring and review mechanisms, and frequency of review will need to be considered to support appropriate focused continuous change. Hand-over timecan be reconsidered with the advent of virtual (or partvirtual) schools so that the break periods between terms become more fluidic. However, if students do undertake home learning through virtual schools, then who holds the responsibilities for home learning will also need to be addressed. In order to fulfil the needs determined by virtual schools, both the shape of networks and the origin of networks will need to be accommodated. Future natures of physical infrastructures will also need to be included in vision and strategies for the future. 


\section{THE CHILD IN THE LEARNING SOCIETY}

A major issue for learning will be the need to potentially reconceptualise the assessment of outcomes of learning. The origin of control of assessment, and the nature of control of assessment are central to this concern.

\section{CONCLUSIONS}

A number of key conclusions emerge:

- The potential for alternative systems has to be established.

- A culture will need to be developed which creates both acceptance and use of the new forms of provision.

- Strengths of traditional and virtual schools must be considered.

- Systems thinking needs to be involved, to challenge traditional systems concepts, and to consider integrative potential.

- Possibilities of different forms of virtual schools in different contexts needs to be considered.

- The development of virtual schools raises issues for all those who will be 'touched' (whether they be students, teachers, parents, business providers, project mangers, or education directors).

- Providers of learning environments can be located outside schools, and needs can be sourced by a variety of providers.

- Individual learners can be the central focus for the provision.

- Learner-focused skills will be needed in the areas of using and creating networking, and a literacy of handling information.

- Teacher-focused skills will be needed for maintaining developments of skills over a period of continuous change.

- Physical infrastructure will need to be introduced to match virtual school needs.

- Assessment needs, methods, and mechanisms will all need to be considered in fundamental ways.

- Support of coursework or project work assessment would match the provision offered by virtual schools.

Virtual school developments raise a number of challenges:

- The relationship and linking of the potential actors involved.

- The challenge for leaders and managers to lead transition.

- Ownership of the intellectual property rights (IPR) of resources developed and how the publishing processes are handled.

- Expressing concepts about virtual schools to teacher educators in ways which enable them to become involved actively.

- Appropriate criteria and evaluation of student outcomes. 